\title{
AVALIAÇÃO DOS IMPACTOS AMBIENTAIS DOS TRATAMENTOS DE RESÍDUOS DE SOLVENTES NO INSTITUTO DE QUÍMICA DA UNIVERSIDADE DE SÃO PAULO
}

\author{
Cláudia R. Martins, Patrícia B. Di Vitta, Liliana Marzorati e Cláudio Di Vitta* \\ Departamento de Química Fundamental, Instituto de Química, Universidade de São Paulo, 05508-900 São Paulo - SP, Brasil
}

Recebido em 13/04/2016; aceito em 09/08/2016; publicado na web em 02/09/2016

\begin{abstract}
ENVIRONMENTAL IMPACTS ASSESSMENT FOR TREATMENTS OF WASTE OF SOLVENTS AT INSTITUTO DE QUÍMICA DA UNIVERSIDADE DE SÃO PAULO. As the result of research work and teaching, the Instituto de Química da Universidade de São Paulo generates 10,000L/year of used solvent mixtures. Although recovery is usually considered an attractive alternative to incineration, a fundamental question remained unanswered: how to ascertain and compare environmental impacts of distillation of a waste mixture of solvents or its disposal by incineration. To this end, after separation of the components of ten solvent mixtures by distillation, Ecosolvent ${ }^{\circledR}$ software was used to compare, for both alternative methods, the EI99 values for some parameters like mass balance, energy and water consumption, gaseous emissions and transportation to the incinerating facility. Results showed that for nine of such mixtures the EI99 parameters were lower for distillation than for incineration.
\end{abstract}

Keywords: Life cycle assessment; environmental impact; solvent recovery; Ecosolvent ${ }^{\circledR}$.

\section{INTRODUÇÃO}

O tratamento de resíduos de produtos químicos gerados em laboratórios de instituições brasileiras de ensino e pesquisa recebeu considerações pioneiras a partir dos anos 90, do século passado, por parte da USP de São Carlos $^{1}$ e da UNICAMP. ${ }^{2}$ Ainda que estas iniciativas tenham sido imbuídas de teor ambientalista, ${ }^{3}$ elas visavam, principalmente, qualificar e dar fim aos enormes passivos de produtos químicos que se achavam acumulados nos laboratórios daquelas instituições. Posteriormente, diversas publicações, em periódicos nacionais, abordaram temas semelhantes, concernentes à implantação de Programas de Gerenciamento de Resíduos de Produtos Químicos em outras instituições, ${ }^{4}$ inclusive nas de ensino médio. ${ }^{5}$ No caso do Instituto de Química da Universidade de São Paulo (IQUSP), um programa semelhante foi iniciado, em 2002, pela implantação, sob os auspícios da FAPESP, ${ }^{6}$ de um laboratório exclusivamente dedicado ao tratamento de resíduos químicos, posteriormente denominado Setor Técnico de Tratamento de Resíduos e Solventes (STRES). Após uma fase de levantamento de ativos e passivos, foi constatado que, entre outros tipos de resíduos, ${ }^{7}$ eram geradas diversas misturas de solventes orgânicos que somavam cerca de 10.000 L / ano. Desde então, conforme pode ser visto pela Tabela 1, o STRES definiu tratamentos para recuperar os componentes de certas misturas. ${ }^{7}$ Por outro lado, a incineração completa da mistura, em incinerador industrial, foi adotada nos casos de componentes de difícil separação.

No entanto, deve-se mencionar que, até o momento, não se havia avaliado o Impacto Ambiental ${ }^{8}$ (IA) relacionado a cada um de tais tratamentos. Portanto, para uma análise inicial, decidiu-se buscar formas de comparar, de maneira quantitativa, o ônus ambiental causado pelo processo de destilação do solvente, visando a recuperação, com a incineração completa da mistura, de modo a se optar pela estratégia menos impactante.

Uma técnica para quantificação do IA de um produto ou de um processo produtivo é a sua Análise de Ciclo de Vida (ACV), a qual leva em conta, sistematicamente, do berço ao túmulo, os impactos do agente sobre os seres humanos e seu entorno. ${ }^{9}$ Pela ACV de um produto ou processo, este é inspecionado considerando-se os IAs

\footnotetext{
*e-mail: vitta@usp.br
}

decorrentes da obtenção das matérias primas para a sua fabricação, a própria fabricação, o uso global de energia e de coadjuvantes requeridos, além do tratamento dos rejeitos originados. Assim, a ACV engloba uma série de etapas que incluem a elaboração de um Inventário de Ciclo de Vida (ICV), bem como a sua avaliação e reavaliação. ${ }^{10}$ Todo este processo, normalmente, é complexo e demorado. Porém, no caso específico de solventes orgânicos e suas misturas, é possível valer-se de modelos mais simples de ICV. Nesta linha, recentemente, diversas publicações apresentaram estudos teóricos para a destinação menos impactante de misturas de solventes dentre as duas opções: a) separação de componentes, por destilação, para reaproveitamento ${ }^{11} \mathrm{e}$ b) a incineração completa da mistura. ${ }^{12,13}$ Outros estudos comparativos para estas duas opções sugerem, ${ }^{14-19}$ de modo geral, a incineração de misturas contendo componentes de baixo IA na produção e a recuperação daqueles cujo IA de produção seja alto. Nestes trabalhos foram utilizados softwares que computam, pelo emprego de bancos de dados internos de ACV, os indicadores de IAs para ambas as alternativas. Dentre estes softwares, o Ecosolvent ${ }^{\circledR}$ tem sido o mais frequentemente empregado. ${ }^{15-19}$

De acordo com o manual do Ecosolvent ${ }^{\circledR}$, este software ${ }^{20}$ é uma ferramenta pública e gratuita para comparar modelos de inventários de ciclo de vida de destilação de solventes com os dos tratamentos térmicos dos mesmos, por incineração em incinerador de produtos químicos perigosos ou em fornos para produção de cimento. Assim, considerando-se um universo de 45 solventes orgânicos, é possível estimar os IAs para destilação até de misturas quaternárias, em processos contínuos ou em bateladas, contendo ou não impurezas salinas ou metálicas. Além disso, podem ser incluídos cálculos de IA resultantes de consumo de energia para uma pré-destilação ou uma simples evaporação para a remoção de sais, por exemplo. Em seguida, o software pode estimar IAs de destilações em batelada ou em contínuo, podendo-se especificar o resultado obtido na destilação, em termos de quantidade e qualidade do destilado na fração de produto obtido. Desta forma, dos impactos nocivos ao ambiente, devidos aos pré-tratamentos, aos consumos de energia nas destilações, ao uso de matérias acessórios, às emissões e aos resíduos da destilação, são subtraídos os não deletérios ao ambiente, associados à recuperação dos solventes, já que esta operação dispensa a sua produção, no futuro. Os valores de IA calculados para 
Tabela 1. Principais tratamentos efetuados no STRES para a recuperação de alguns solventes

\begin{tabular}{|c|c|c|}
\hline Mistura & Tratamento(s) & Solvente(s) recuperado(s) \\
\hline \multirow[t]{2}{*}{ acetonitrila e água } & congelamento/destilação & acetonitrila/água (azeótropo) \\
\hline & secagem/destilação & acetonitrila \\
\hline acetona e etanol & destilação & acetona e etanol \\
\hline acetato de etila e metanol & lavagem com solução ácida/secagem/destilação & acetato de etila \\
\hline ciclo-hexano e metanol & congelamento/decantação/destilação & ciclo-hexano e metanol \\
\hline clorofórmio e acetona & lavagem com solução ácida/secagem/destilação & clorofórmio \\
\hline clorofórmio e metanol & lavagem com solução ácida/secagem/destilação & clorofórmio \\
\hline diclorometano e acetona & lavagem com solução ácida/secagem/destilação & diclorometano \\
\hline diclorometano e metanol & lavagem com solução ácida/secagem/destilação & diclorometano \\
\hline etanol e água & destilação & etanol \\
\hline hexanos e acetato de etila & $\begin{array}{l}\text { degradação química do acetato de etila/lavagem com água/secagem/destilação } \\
\text { biodegradação do acetato de etila/lavagem com água/secagem/destilação }\end{array}$ & hexanos \\
\hline n-hexano e acetato de etila & $\begin{array}{l}\text { degradação química do acetato de etila/lavagem com água/secagem/destilação } \\
\text { biodegradação do acetato de etila/lavagem com água/secagem/destilação }\end{array}$ & n-hexano \\
\hline hexanos e acetona & lavagem com solução ácida/secagem/destilação & hexanos \\
\hline hexanos e diclorometano & destilação & hexanos e diclorometano \\
\hline hexanos e isopropanol & lavagem com solução ácida/secagem/destilação & hexanos \\
\hline metanol e água & destilação & metanol \\
\hline tolueno e acetona & lavagem com solução ácida/secagem/destilação & tolueno \\
\hline tolueno e acetato de etila & destilação & tolueno \\
\hline
\end{tabular}

as destilações podem, então, ser comparados com os da incineração das misturas brutas, em incinerador industrial de produtos químicos, ou em fornos de indústrias de cimento. No inventário da incineração, dos aspectos nocivos causados pela destruição dos solventes, pelas emissões de $\mathrm{CO}_{2}$, pelo transporte dos solventes ao incinerador e pelo uso de coadjuvantes, é possível subtrair o efeito benéfico da geração de eletricidade e vapor, resultante da queima do solvente, em substituição a combustíveis fósseis.

No que tange aos indicadores de IA, o Eco-indicador $99^{21}$ (EI99) tem sido constantemente empregado. ${ }^{15-18}$ Resumidamente, pode-se dizer que o EI99 exprime, de maneira ponderada, em valores numéricos chamados ecopontos, os danos à saúde humana, ao ecossistema e à degradação dos recursos naturais. Um valor positivo de EI99 indica dano ambiental e um negativo indica efeito benéfico ao ambiente. No caso de solventes, de modo geral, os valores descritivos médios de EI99, para produção, variam ${ }^{15}$ de 0,135 (para o metanol) a 0,900 (para o tetra-hidrofurano). Pelo emprego do Ecosolvent ${ }^{\circledR}$, os estudos antes mencionados ${ }^{15-19}$ apresentaram a sugestão de incinerarem-se misturas contendo componentes com baixo EI99 de produção e recuperarem-se aqueles cujos EI99 de produção sejam altos.

Uma vez que o Ecosolvent ${ }^{\circledR}$ é de uso livre, decidiu-se empregá-lo para comparar, via os EI99, os IAs decorrentes dos processos de destilação de solventes, efetuados no STRES, em comparação com a incineração completa das misturas.

\section{RESULTADOS E DISCUSSÃO}

Para a avaliação dos IAs foram selecionados os lotes 1 - 10 (Tabela 2) que representam as misturas de solventes mais corriqueiramente tratadas no STRES.

As misturas dos lotes 1 - 10 foram destiladas; os balanços de massa e os consumos de energia e de água, nas destilações, estão apresentados na Tabela 3 .

Usando-se os dados das Tabelas 2 e 3 , foram calculados os valores de EI99 tanto para a destilação como para a incineração de cada lote. No material suplementar referente a este trabalho acham-se os gráficos gerados pelo Ecosolvent $\AA$, segundo os dados das Tabelas 2 e 3, para as destilações das misturas dos lotes 1 - 10, em comparação com a incineração completa das misturas.

A Tabela 4 apresenta os valores médios de EI99 para alguns parâmetros de recuperação em comparação com os da incineração, levando-se em consideração o consumo de energia, o uso de coadjuvantes, as emanações e, para a incineração, o transporte até o incinerador industrial de produtos químicos perigosos.

Tabela 2. Lotes de misturas destiladas: origens e composições

\begin{tabular}{|c|c|c|c|}
\hline Lote & Mistura / origem & Composição inicial (em \% de massa) & $\begin{array}{c}\text { Massa(s) de solvente(s) na } \\
\text { mistura (em kg) }\end{array}$ \\
\hline 1 & n-hexano e diclorometano / eluentes para cromatografias em coluna & 50 de n-hexano e 44 de diclorometano & 6,1 de diclorometano e 7,0 de n-hexano \\
\hline 2 & n-hexano e diclorometano / eluentes para cromatografias em coluna & 55 de n-hexano e 39 de diclorometano & 3,3 de diclorometano e 3,1 de n-hexano \\
\hline 3 & diclorometano e metanol / extrações líquido-líquido & 87 de diclorometano e 13 de metanol & 15,1 de diclorometano e 2,2 de metanol \\
\hline 4 & diclorometano e n-hexano / eluentes para cromatografias em coluna & 95 de diclorometano & 3,7 de diclorometano \\
\hline 5 & ciclo-hexano / solvente de reação & 99 de ciclo-hexano & 6,2 de ciclo-hexano \\
\hline 6 & clorofórmio / extrações líquido-líquido & 99 de clorofórmio & 6,8 de clorofórmio \\
\hline 7 & etanol / lavagem de vidrarias & 90 de etanol & 3,2 de etanol \\
\hline 8 & tolueno / solvente de reação & 99 de tolueno & 3,2 de tolueno \\
\hline 9 & etanol / lavagem de vidrarias & 88 de etanol & 7,1 de etanol \\
\hline 10 & etanol / lavagem de vidrarias & 83 de etanol & 6,7 de etanol \\
\hline
\end{tabular}


Tabela 3. Teores e massas dos solventes recuperados das misturas dos lotes 1 - 10; tipos de enchimento e dimensões de colunas de destilação usadas; consumos de energia e água nas destilações

\begin{tabular}{|c|c|c|c|c|}
\hline Lote & $\begin{array}{l}\text { Concentração(ões) média(s) (em \%) do(s) } \\
\text { solvente(s) recuperado(s) na(s) fração(ões) }\end{array}$ & $\begin{array}{c}\text { Massa(s) recuperada(s) (em kg) de solvente(s) } \\
\text { na(s) fração(ôes) }\end{array}$ & $\begin{array}{c}\text { Tipo de enchimento / } \\
\text { dimensões da coluna } \\
\text { (comprimento }(\mathrm{m}) \mathrm{x} \text { diâmetro } \\
\text { interno }(\mathrm{cm}))\end{array}$ & $\begin{array}{l}\text { Energia }(\mathrm{kWh}) / \\
\text { Âgua }(\mathrm{L})\end{array}$ \\
\hline 1 & $\begin{array}{l}\text { fração 1: } 77 \text { de diclorometano; } \\
\text { fração 2: } 100 \text { de n-hexano }\end{array}$ & $\begin{array}{l}\text { fração 1: 6,0 de diclorometano; } \\
\text { fração 2: } 5,9 \text { de n-hexano }\end{array}$ & anéis de Raschig / 3 × 8 & $232 / 40$ \\
\hline 2 & $\begin{array}{l}\text { fração 1: } 91 \text { de diclorometano; } \\
\quad \text { fração 2: } 97 \text { de n-hexano }\end{array}$ & $\begin{array}{l}\text { fração 1: } 3,0 \text { de diclorometano; } \\
\quad \text { fração } 2: 3,0 \text { den-hexano }\end{array}$ & spinning band / 0,9 x 4 & $86 / 0$ \\
\hline 3 & $\begin{array}{l}\text { fração 1: } 95 \text { de diclorometano; } \\
\text { fração 2: } 99 \text { de metanol }\end{array}$ & $\begin{array}{c}\text { fração 1: } 14,7 \text { de diclorometano; fração } 2: 2,2 \text { de } \\
\text { metanol }\end{array}$ & anéis de Raschig / 3 x 8 & $170 / 0$ \\
\hline 4 & 98 de diclorometano & 3,6 de diclorometano & anéis de Raschig / 1 x 4 & $24 / 0$ \\
\hline 5 & 98 de ciclo-hexano & 6,1 de ciclo-hexano & anéis de Raschig / 1 x 4 & $68 / 0$ \\
\hline 6 & 98 de clorofórmio & 6,6 de clorofórmio & anéis de Raschig / 1 x 4 & $62 / 0$ \\
\hline 7 & 86 de etanol & 2,8 de etanol & Vigreux / 0,37 x 2 & $56 / 0$ \\
\hline 8 & 100 de tolueno & 3,2 de tolueno & anéis de Raschig / 1 x 4 & $26 / 0$ \\
\hline 9 & 87 de etanol & 6,2 de etanol & anéis de Raschig / 1 x 4 & $133 / 0$ \\
\hline 10 & 89 de etanol & 6,0 de etanol & anéis de Raschig / 1 x 4 & $117 / 0$ \\
\hline
\end{tabular}

Tabela 4. Valores médios de EI99 para alguns parâmetros inerentes à recuperação do solvente e à incineração de toda a mistura dos lotes 1 - 10

\begin{tabular}{|c|c|c|c|c|c|c|c|}
\hline \multirow[b]{2}{*}{ Lote } & \multirow{2}{*}{$\begin{array}{l}\text { Solvente } \\
\text { recuperado }\end{array}$} & \multicolumn{6}{|c|}{ Parâmetros para destilação / incineração } \\
\hline & & Produção & Recuperação & Energia & Coadjuvantes & $\begin{array}{l}\text { Emanações e } \\
\text { resíduos }\end{array}$ & Transporte \\
\hline \multirow[t]{2}{*}{1} & diclorometano & $3,3 / 3,3$ & $-1,3 / 0,0$ & $1,8 / 0,0$ & $0,0 / 0,9$ & $4,8 / 0,2$ & $0,0 / 0,6$ \\
\hline & n-hexano & $3,3 / 3,3$ & $-1,2 / 0,0$ & $1,8 / 0,0$ & $0,0 / 1,0$ & $6,4 / 0,1$ & $0,0 / 0,6$ \\
\hline \multirow[t]{2}{*}{2} & diclorometano & $-1,5 / 1,5$ & $-0,6 / 0,0$ & $0,7 / 0,0$ & $0,0 / 0,6$ & $0,2 / 0,1$ & $0,0 / 0,6$ \\
\hline & n-hexano & $1,6 / 1,6$ & $-0,8 / 0,0$ & $0,7 / 0,0$ & $0,0 / 0,5$ & $0,8 / 0,1$ & $0,0 / 0,6$ \\
\hline 3 & diclorometano & 0,0 & $-3,6 / 0,0$ & $1,6 / 0,0$ & $1,4 / 3,6$ & $0,3 / 0,0$ & $0,0 / 0,7$ \\
\hline 4 & diclorometano & 6,4 & $-0,9 / 0,0$ & $0,3 / 0,0$ & $0,0 / 0,9$ & $0,1 / 0,1$ & $0,0 / 0,6$ \\
\hline 5 & ciclo-hexano & 0,0 & $-1,8 / 0,0$ & $0,6 / 0,0$ & $0,0 / 0,0$ & $0,0 / 0,1$ & $0,0 / 0,6$ \\
\hline 6 & clorofórmio & $2,2 / 2,2$ & $-2,1 / 0,0$ & $0,6 / 0,0$ & $0,5 / 0,7$ & $0,1 / 0,1$ & $0,0 / 0,6$ \\
\hline 7 & etanol & $0,6 / 0,6$ & $-0,5 / 0,0$ & $0,4 / 0,0$ & $0,0 / 0,0$ & $0,0 / 0,1$ & $0,0 / 0,6$ \\
\hline 8 & tolueno & $0,9 / 0,9$ & $-0,9 / 0,0$ & $0,2 / 0,0$ & $0,2 / 0,0$ & $0,0 / 0,1$ & $0,0 / 0,7$ \\
\hline 9 & etanol & $1,3 / 1,3$ & $-1,0 / 0,0$ & $1,0 / 0,0$ & $0,5 / 0,0$ & $0,1 / 0,1$ & $0,0 / 0,6$ \\
\hline 10 & etanol & $1,2 / 1,2$ & $-1,0 / 0,0$ & $0,7 / 0,0$ & $0,6 / 0,0$ & $0,1 / 0,1$ & $0,0 / 0,6$ \\
\hline
\end{tabular}

O cálculo global de EI99 médio para cada lote, com base na Tabela 4, está resumido na Tabela 5.

Embora exista um portal $^{22}$ criado para identificar e disseminar iniciativas de ACV nacionais, sob a organização do Instituto Brasileiro de Informação em Ciência e Tecnologia, não foi possível nele encontrar um banco de dados concernente a solventes. Assim, utilizando-se o Ecosolvent ${ }^{\circledR}$ (que por ser europeu pode apresentar certa especificidade regional de dados de ACV) e observando-se os valores de EI99 da Tabela 5, conclui-se que todos os tratamentos apresentam IAs diferenciados e superiores a zero. Em 9 casos (lotes 2 - 10) a separação dos componentes das misturas, por destilação, foi ambientalmente menos impactante do que a incineração da mistura bruta. Apenas no caso do lote 1 a destilação mostrou-se mais impactante do que a incineração. Levando-se em consideração que este lote representa apenas apenas $6 \%$ das misturas que o STRES recebe para tratar, pode-se afirmar que a recuperação dos seus componentes seria interessante apenas se fosse empregada uma coluna de destilação eficiente como, por exemplo, a do tipo spinning band. Isto se mostrou verdadeiro para o lote 2 , de composição semelhante à do lote $1 \mathrm{e}$ se deveu, em parte, ao fato de tal equipamento render, em menor tempo,
Tabela 5. Valores médios de EI99 globais para destilação e para incineração, referentes aos lotes $1-10$

\begin{tabular}{ccc}
\hline Lote & Destilação & Incineração \\
\hline 1 & 8,6 (diclorometano) $/$ & 5,0 (diclorometano) $/$ \\
& 10,3 (n-hexano) & 5,0 (n-hexano) \\
2 & 1,8 (diclorometano) & 2,8 (diclorometano) $/$ \\
& 2,3 (n-hexano) & 2,8 (n-hexano) \\
3 & 3,6 (diclorometano) & 8,2 (diclorometano) \\
4 & 0,5 & 3,6 \\
5 & 0,7 & 2,6 \\
6 & 1,3 & 3,7 \\
7 & 0,5 & 1,3 \\
8 & 0,5 & 1,7 \\
9 & 1,9 & 2,0 \\
10 & 1,6 & 1,9 \\
\hline
\end{tabular}

destilados mais puros, o que implicou em processo com menor gasto energético. Porém, o que mais impactou na destilação do lote 1 foi o gasto de água para a refrigeração do condensador (ver emanações 
e resíduos; Tabela 4), o que foi evitado nas outras destilações pelo reúso do fluído.

Para os lotes 2 - 10, de modo geral, a recuperação dos solventes (EI99 < 0) compensou, pelo menos em parte, o IA de produção dos mesmos. No entanto, estes resultados não devem ser extrapolados para qualquer fonte geradora, pois a incineração poderia apresentar um IA menor caso a energia liberada na queima fosse aproveitada, para aquecimento, no incinerador, o que não parece ser uma funcionalidade disponível amplamente nestes equipamentos, no Brasil. Por outro lado, para fontes geradoras de resíduos muito distantes do incinerador, o IA do transporte pode afetar desfavoravelmente o processo de incineração.

Ainda que, neste trabalho, não tenham sido comparados os custos relativos às duas opções de tratamento, é importante ponderar que, no caso das destilações, há a necessidade de aquisição e de instalação de equipamentos, além de remuneração dos operadores. Porém, parte deste custo inicial pode ser amortizado em função das quantidades de solventes recuperados e de seus valores de mercado. Já no que diz respeito à incineração em incineradores industriais, os custos são sempre proporcionais à massa da carga a ser incinerada (mistura de solventes e embalagens) e variam, segundo têm-se notado, com a cotação do dólar americano. Adicionalmente, deve ser considerado tanto o custo do transporte da carga ao incinerador, a ser realizado por empresa especificamente licenciada, como o das embalagens, as quais devem ser homologadas para este fim. ${ }^{23}$ Além disso, aspectos burocráticos relativos à obtenção das licenças de órgãos ambientais para a destinação das misturas ao incinerador, bem como das cinzas resultantes ao aterro industrial, podem tornar o processo demorado e, também, mais custoso.

\section{CONCLUSÃO}

O uso do software Ecosolvent ${ }^{\circledR}$ mostrou-se útil para o STRES definir, caso a caso, qual alternativa de tratamento é ambientalmente menos impactante para uma corrente de solventes orgânicos, em função de suas quantidades, eficácias das aparelhagens de destilação disponíveis e distância ao incinerador industrial. Para a maioria dos casos estudados, a destilação para a recuperação de solventes mostrou-se menos impactante, justificando o investimento em aparelhagens e mão de obra. Porém, uma análise crítica dos resultados indica que pode haver vantagem em incinerar, em vez de destilar, caso a energia gerada pela incineração do material possa ser aproveitada em processos produtivos e o incinerador se encontre próximo à fonte geradora. Cabe ressaltar, no entanto, que esta reciclagem energética é ainda incipiente em nosso país. Este fato, aliado a aspectos legais e burocráticos relacionados com a incineração, indica, claramente, que a alternativa de escolha para as diversas instituições de ensino e pesquisa ainda é a recuperação dos solventes por elas gerados.

\section{PARTE EXPERIMENTAL}

\section{Análises}

As análises cromatográficas gás-líquido foram efetuadas usando-se hélio como gás de arraste, em um cromatógrafo Shimadzu-GC17A equipado com uma coluna $D B 624$, conectada a detector de ionização de chama. As composições relativas dos solventes, nas misturas dos lotes 1 - 4, foram determinadas por cromatografia gás-líquido, a partir de curvas de calibração construídas com amostras sintéticas (em \% de massa) dos dois solventes. Os teores de ciclo-hexano (lote 5), clorofórmio (lote 6) e tolueno (lote 8) foram determinados por cromatografia gás-líquido diretamente a partir das integrações das áreas \% dos sinais cromatográficos. Os teores de etanol, nas frações dos lotes 7, 9 e 10, foram determinados a partir das densidades das amostras.

\section{Destilações}

Todas as colunas de destilação eram encamisadas a vácuo. A destilação do lote 2 foi efetuada em sistema BR Instruments-9600 $S B A$, equipado com manta elétrica de $650 \mathrm{~W} .{ }^{24}$ As potências (W) das mantas elétricas usadas nas outras destilações eram: 2260 para os lotes 1 e 3; 1600 para os lotes 5, 6, 9 e 10; 660 para os lotes 4, 7 e 8. Nenhum lote recebeu tratamento prévio à destilação. No caso do lote 1 , foi usada água corrente para refrigeração do condensador. No caso dos outros lotes, para resfriamento e reuso da água de refrigeração dos condensadores dos sistemas de destilação, foi utilizado um banho Marconi-MA184, de $1800 \mathrm{~W}$ de potência.

\section{Cálculos}

O software Ecosolvent ${ }^{\circledR}$ v.1.0.1 foi descarregado do sítio da interne $\mathrm{t}^{20} \mathrm{e}$ instalado em computador empregando o sistema operacional Windows 7®; Para cada lote, foram gerados os gráficos de ecopontos EI99 versus destilação e incineração (no formato box-wishker), os quais se acham disponíveis na parte suplementar. Para os cálculos dos valores de EI99 foram inseridas as massas de cada solvente nas misturas iniciais e nas frações recuperadas, com bases nas análises efetuadas (ver Tabelas 2 e 3). Os cálculos de consumo de energia elétrica nas destilações levaram em consideração a potência máxima consumida por todos os equipamentos empregados (manta de aquecimento e sistema de refrigeração de água), em função do tempo de uso dos mesmos (ver Tabela 3). Para o cálculo do IA do transporte, nas incinerações, foi considerado o uso de caminhão e um percurso de $20 \mathrm{~km}$, que corresponde à distância entre o STRES e Taboão da Serra/SP, local em que se encontra o incinerador de produtos químicos perigosos, atualmente contratado pelo IQUSP.

\section{MATERIAL SUPLEMENTAR}

Gráficos gerados pelo software Ecosolvent $\AA$, para comparação de ecopontos EI99 entre destilação e incineraçãos referentes aos lotes 1 a 10, são acessíveis pelo sítio http://quimicanova.sbq.org.br/.

\section{AGRADECIMENTOS}

Agradecemos à FAPESP pelo apoio concedido referente ao processo FAPESP 2001/01221-3.

\section{REFERÊNCIAS E NOTAS}

1. Alberguini, L. B. A.; Silva, L. C.; Rezende, M. O.; Quim. Nova 2003, 26, 291.

2. Jardim, W. F.; Quim. Nova 1998, 21, 671.

3. As preocupações com aspectos ambientais, de forma ampla, tornaramse objeto formal de atenção dos americanos, em 1969, quando eles definiram uma política nacional relacionada ao meio ambiente e, em 1970, fundaram uma agência regulamentadora dedicada ao assunto (Caldwell, L. K.; The National Environmental Policy Act-An Agenda for the Future; Indiana Press University, Bloomington, USA, 1998.). Na Comunidade Europeia, após a Declaração de Paris, em 1972, diversas leis ambientais foram lá aprovadas (Brandte, E. V. Em Europe's Global Role: External Policies of the European Union; Orbie, J. ed.; Ashgate Publishing Limited: England, 2008, cap. 7). No Brasil, as questões ambientais foram abordadas de modo tardio e restrito quando, em 1985, foi promulgada da Lei de Zoneamento Industrial 
(http://presrepublica.jusbrasil.com.br/legislacao/128314/lei-6803-80, acessada em Fevereiro de 2016, referente à Lei n. ${ }^{\circ} 6803$ de 2 de julho de 1980.), que reservou à União o poder de autorizar, baseado em estudos especiais de alternativas e de avaliações de impacto, a implantação de zonas de uso estritamente industrial tais como polos petroquímicos, cloroquímicos, carboquímicos e instalações nucleares. Mais tarde, ao ser estabelecida a Política Nacional do Meio Ambiente (http://www. planalto.gov.br/ccivil_03/leis/L6938.htm, acessada em Agosto de 2016, referente à Lei n. ${ }^{\circ} 6938$ de 31 de agosto de 1981) e criado o Conselho Nacional do Meio Ambiente (CONAMA; http://www.planalto.gov. br/ccivil_03/decreto/antigos/d99274.htm, acessada em Fevereiro de 2016, referente ao Decreto n. ${ }^{\circ} 9274$ de 6 de junho de 1990), foi a este outorgada competência para fixar os critérios para a exigência da avaliação de impacto ambiental antes da liberação do licenciamento de um empreendimento (http://www.mma.gov.br/port/conama/res/res86/ res0186.html, acessada em Fevereiro de 2016, referente à Resolução CONAMA 001 de 23 de janeiro de 1986). Contrastando com este tardio despertar para as questões ambientais, a Constituição Brasileira (http:// www.imprensaoficial.com.br/PortalIO/download/pdf/Constituicoes_ declaracao.pdf, acessada em Fevereiro de 2016, conforme o Inciso IV, do parágrafo $1^{\circ}$, artigo 225 do capítulo VI ) foi pioneira ao exigir o estudo prévio de impacto ambiental para instalação genérica de obra ou atividade com potencial para causar degradação significativa do meio ambiente.

4. Tavares, G. A.; Bendassoli, J. A.; Quim. Nova 2005, 28, 732; Gonçalves, M. S.; Kummer, L.; Sejas, M. I.; Rauen, T. G.; Bravo, C. E. C.; Rev. Brasil. Cienc. Amb. 2010, 15, 80; Pacheco, E. V.; Hemais, C. A.; Fontoura, G. A. T.; Rodrigues, F. A.; Polim.: Cien. Tecnol. 2003, 13, 14; Afonso, J. C.; Silveira, J. A.; Oliveira, A. S. Lima, R. M. G.; Quim. Nova 2005, 28 , 157; Imbroisi, D.; Guaritá-Santos, A. J. M.; Barbosa, S. S.; Shintaku, S. F.; Monteiro, H. J.; Ponce, G. A. E.; Furtado, J. G.; Tinoco, C. J.; Mello, D. C.; Machado, P. F. L.; Quim. Nova 2006, 29, 404; Giloni-Lima, P. C. Lima, V. A.; Quim. Nova 2008, 31, 1595.

5. Silva, A. F.; Soares, T. R. S.; Afonso, J. C.; Quim. Nova Esc. 2010, 32, 37.

6. Processo FAPESP 2001/01221-3: Tratamento e Gerenciamento de Resíduos Químicos no IQUSP.

7. De Conto, S. M.; Gestão de resíduos em universidades, EDUCS, 2010, p. 207.
8. O impacto ambiental, segundo o CONAMA (conforme consta no sítio http://www.mma.gov.br/port/conama/res/res86/res0186.html, acessado em Fevereiro de 2016, referente à Resolução 001 de 23 de janeiro de 1986), é qualquer alteração das propriedades físicas, químicas e biológicas do meio ambiente que, direta ou indiretamente, afetem a saúde, a segurança e o bem-estar da população, as atividades sociais e econômicas, a biota (flora e fauna), as condições estéticas e sanitárias do meio ambiente e a qualidade dos recursos ambientais.

9. Raymond, M. J.; Slater, C. S.; Savelski, M. J.; Green Chem. 2010, 12, 1826.

10. Willers, C. D.; Rodrigues, L. B.; Silva, C. A.; Production 2013, 23, 436.

11. Capello, C.; Hellweg, S.; Badertscher, B.; Betschart H.; Hungerbühler, K.; Environ. Sci. Technol. 2005, 39, 5885.

12. Seyler, C.; Hellweg, S.; Monteil, M.; Hungerbühler, H.; Int. J. Life Cycle Assess. 2005, 10, 120.

13. Seyler, C.; Hofstetter, T. B.; Hungerbühler, K.; J. Cleaner Prod. 2005, $13,1211$.

14. Jimenez-Gonzalez, C.; Overcash, M.; Curzons, A.; J. Chem. Technol. Biotechnol., Chem. Technol. 2001, 76, 707.

15. Amelio, A.; Genduso, G.; Vreysen, S.; Luis, P.; Van der Bruggen, B.; Green Chem. 2014, 16, 3045.

16. Capello, C.; Hellweg, S.; Badertscher, B.; Betschart H.; Hungerbühler, K.; J. Ind. Ecol. 2007, 11, 26.

17. Capello, C.; Hellweg, S.; Hungerbühler, K.; J. Ind. Ecol. 2008, 12, 111.

18. Luis, P.; Amelio, A.; Vreysse, S.; Calabro, V.; Van der Bruggen, B.; Int. J. Life Cycle Assess. 2013, 18, 1048.

19. Cavanagh, E. J.; Savelski, M. J.; Slater, C. S.; Chem. Eng. Res. Des. 2014, 92, 1942.

20. http://www.sust-chem.ethz.ch/tools/ecosolvent; Copyright by ETH Zurich, Christian Capello, Stefanie Hellweg, Konrad Hungerbühler, 1.10.2006.

21. https://www.pre-sustainability.com/eco-indicator-99-manuals, acessada em Fevereiro de 2016.

22. acv.ibict.br/portal, acessada em Fevereiro de 2016.

23. http://www.antt.gov.br/index.php/content/view/1420/Resolucao_420. html, acessada em Março de 2016.

24. https://www.brinstrument.com/fractional-distillation/lab-scale-fractionaldistillation-description.php, acessada em Junho de 2016. 